\title{
PENGARUH MODUL PEMBELAJARAN IPA TERINTEGRASI NILAI AGAMA TERHADAP PENGEMBANGAN KARAKTER MANDIRI SISWA
}

\author{
Intan Rahma Utami ${ }^{1}$, Retno Triwoelandari ${ }^{2}$, M. Kholil Nawawi ${ }^{3}$ \\ intanrahmau@gmail.com¹, retnotriwoelandari@fai-uika.ac.id², \\ kholil@fai.uika-bogor.ac.id ${ }^{3}$ \\ PGMI, FAI, Universitas Ibn Khaldun Bogor ${ }^{123}$
}

\begin{abstract}
Abstrak: Pendidikan dalam Islam mengajarkan untuk mendidik anak secara mandiri, karena pada akhirnya nanti masing-masing individulah yang dimintai pertanggung jawaban atas apa yang diperbuatnya di dunia. Berdasarkan hasil observasi, kegiatan pembelajaran di kelas hanya sebatas penyampaian materi tanpa mengintegrasikan nilainilai Islam. Tujuan dari penelitian ini adalah untuk mengetahui pengaruh modul pembelajaran IPA terintegrasi nilai agama dalam mengembangkan karakter mandiri siswa. Penelitian ini menggunakan metode kuasi eksperimen dengan desain eksperimen pretest-posttest control group design. Sampel yang digunakan pada penelitian ini sebanyak 64 siswa kelas 5 sekolah dasar. Teknik pengumpulan data yaitu dengan melakukan observasi serta analisis data menggunakan software SPSS 20 for window. Hasil penelitian menunjukkan rata-rata perbedaan pretest dan posttest sebesar 7,2069 pada kelas eksperimen dan 3,5455 pada kelas kontrol. Hal ini menunjukan bahwa modul pembelajaran IPA terintegrasi nilai agama berpengaruh dalam pengembangan karakter mandiri.
\end{abstract}

Kata kunci: Modul, Integrasi agama, Karakter mandiri.

\section{THE INFLUENCE OF SCIENCE LEARNING MODULES INTEGRATED RELIGIOUS VALUES TOWARDS THE INDEPENDENT CHARACTER DEVELOPMENT}

\begin{abstract}
Education in Islam teaches to educate children independently, because in the end each individual will be held accountable for what he has done in the world. Based on observations, classroom learning activities are limited to the delivery of material without integrating Islamic values. The purpose of this study was to determine the effect of integrated science learning modules on religious values in developing students independent character. The study used the quasi-experimental design of the pretestposttest control group design. The sample used in this study was 64 students in 5 grade primary school. Data collection techniques are using the observation and data analysis using SPSS 20 for window software. The results showed that the average difference in pretest and posttest was 7.2069 in the experimental class and 3.5455 in the control class.
\end{abstract}


Intan, Retno, M. Kholil. Pengaruh Modul Pembelajaran IPA...

This shows that the integrated science learning module of religious values influences the development of independent character.

Keywords: Module, Religious integration, Independent character.

\section{PENDAHULUAN}

Menurut Gagne dalam Huda (2014: 3) pembelajaran merupakan proses modifikasi dalam kapasitas manusia yang bisa dipertahankan dan ditingkatkan levelnya. Selama proses ini, seseorang bisa memilih untuk melakukan perubahan atau tidak sama sekali terhadap apa yang ia lakukan. Ketika pembelajaran diartikan sebagai perubahan dalam perilaku, tindakan, cara dan performa hal itu dapat kita ketahui dengan cara mengobservasi perilaku tersebut.

Pembelajaran mengandung arti setiap kegiatan yang dirancang untuk membantu seseorang mempelajari suatu kemampuan dan nilai yang baru. Proses pembelajaran yang pada awalnya meminta guru untuk mengetahui kemampuan dasar yang dimiliki oleh siswa meliputi kemampuan dasarnya, motivasinya, latar belakang akademisnya, dan lain sebagainya. Kesiapan guru untuk mengenal karakteristik siswa dalam pembelajaran merupakan modal utama penyampaian bahan belajar dan menjadi indikator suksesnya pelaksanaan pembelajaran.

Dari beberapa pendapat di atas dapat dilihat bahwa dalam kegiatan pembelajaran yang menjadi fokus utama adalah mengenali karakter siswa untuk menentukan sumber belajar atau pun bahan ajar yang akan digunakan dalam proses pembelajaran sehingga tujuan dari pembelajaran tersebut dapat tercapai. Namun pada kenyataannya masih banyak pihak yang belum menyadari akan hal tersebut, sehingga bahan ajar yang digunakan belum sepenuhnya dapat mengembangkan karakter yang dimiliki siswa. Menurut Istanti (2015: 3) proses pembelajaran melibatkan berbagai pihak, tidak hanya melibatkan pendidik dan siswa, namun peran dari bahan ajar juga sangat dibutuhkan dalam proses pembelajaran. Bahan ajar dapat berfungsi dalam pembelajaran individual yang dapat digunakan untuk menyusun dan mengawasi proses pemerolehan informasi peserta didik.

Salah satu bahan ajar tertulis dan termasuk ke dalam kategori bahan ajar cetak yang disiapkan dalam bentuk kertas yang dapat berfungsi untuk pembelajaran dan penyampaian informasi adalah modul. "Modul merupakan sebuah bahan ajar yang 
Intan, Retno, M. Kholil. Pengaruh Modul Pembelajaran IPA...

disusun secara sistematis dengan bahasa yang mudah dipahami oleh peserta didik sesuai tingkat pengetahuan dan usia mereka, agar mereka dapat belajar sendiri (mandiri) dengan bantuan atau bimbingan yang minimal dari pendidik" (Prastowo, 2014: 106). Seperti yang dijelaskan oleh Ditasari, Peniati, dan Kasmui (2013: 331) salah satu tujuan penyusunan modul adalah menyediakan bahan ajar yang sesuai dengan tuntutan kurikulum dengan mempertimbangkan kebutuhan siswa.

Sementara itu, dalam realitas pendidikan di lapangan banyak pendidik yang masih menggunakan bahan ajar yang konvensional, yaitu bahan ajar yang dapat langsung digunakan tanpa merencanakan dan menyusun sendiri target atau kompetensi apa yang akan dicapai siswa. Tenaga pendidik juga belum dapat mengimbangi pemberian materi yang disertai dengan penanaman nilai-nilai moral dan agama sehingga hal tersebut kerap kali dilewatkan padahal nilai moral dan agama juga tidak kalah penting untuk terus diberikan kepada siswa agar siswa tidak berperilaku menyimpang terhadap ajaran agama yang telah ditentukan. Hal ini sejalan dengan pendapat Gunawan, Suyitno, dan Supriyadi (2018: 341) yang mengatakan bahwa seorang anak harus dibekali dengan pendidikan karakter sejak dini, agar bisa ditekankan dalam kehidupan sosial untuk berperilaku baik serta menciptakan seorang yang berpendidikan, berkarakter, kreatif, dan cerdas. Selain itu, anak juga diharapkan mampu mengaplikasikan nilai-nilai luhur dalam bangsa dan agama.

Pendidikan dalam Islam mengajarkan untuk mendidik anak secara mandiri. Rasulullah sangat memperhatikan pertumbuhan potensi anak, beliau membangun sifat percaya diri dan mandiri pada anak agar ia bisa bergaul dengan berbagai unsur masyarakat yang selaras dengan kepribadiannya, karena pada akhirnya nanti masingmasing individulah yang dimintai pertanggung jawaban atas apa yang diperbuatnya di dunia.

Firman Allah SWT yang termaktub dalam Al-Qur'an surat Al-Mukminun ayat 62:

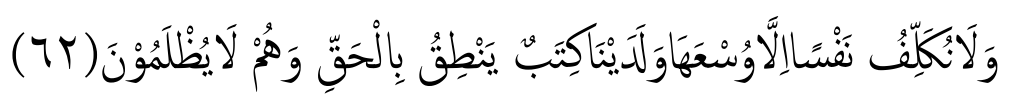

Artinya, "Kami tiada membebani seseorang melainkan menurut kesanggupannya, yang pada sisi Kami ada kitab yang berbicara benar, dan mereka telah dianiaya.” (Q.S. Al-Mukminun: 62) 
Intan, Retno, M. Kholil. Pengaruh Modul Pembelajaran IPA...

Ayat tersebut menjelaskan bahwa individu tidak akan mendapatkan suatu beban di atas kemampuannya sendiri tetapi Allah Maha Tahu dengan tidak memberi beban individu melebihi batas kemampuan individu itu sendiri, karena itu individu dituntut untuk mandiri dalam menyelesaikan persoalan dan pekerjaannya tanpa banyak tergantung pada orang lain.

Berdasarkan penelitian yang dilakukan oleh Fenti Nurjanah dalam Jurnal Ilmiah Pendidikan Dasar (2018: 180) merosotnya karakter religius siswa di lingkungan masyarakat ditunjukkan dengan banyaknya tawuran antar siswa, tindak kekerasan antar siswa, membully teman sepulang sekolah, dan banyak fakta lain yang berbau negatif terkait karakter anak bangsa zaman sekarang. Untuk mengatasi permasalahan tersebut, penulis melakukan integrasi pada mata pelajaran umum khususnya sains dan nilai-nilai Islam yang dilakukan untuk meningkatkan karakter anak. Pengintegrasian tersebut dilakukan melalui produk yang dikembangkan penulis dalam bentuk modul sebagai suplemen bahan ajar yang digunakan guru dalam proses pembelajaran.

Penelitian lain yang dilakukan oleh Silviana Nur Faizah dalam jurnal at-thulab (2017- 103) menjelaskan bahwa dengan berfikir tentang penciptaan langit dan bumi sebagai sarana menambah Iman dan Taqwa kepada Allah SWT. satu dari ilmu yang mempelajari tentang penciptaan langit dan bumi adalah Ilmu Pengetahuan Alam (IPA). Secara normatif, kedudukan IPA perlu dikawal dengan agama supaya tidak terjadi penyalahgunaan IPA, sehingga IPA dapat mendatangkan kemaslahatan di dunia. Pada dasarnya agama dan IPA tidak dapat berdiri sendiri, inilah yang dikenal sebagai konsep Integrasi Islam dan Sains.

Dari beberapa penjelasan serta masalah yang ditemukan oleh peneliti maka dalam dunia pendidikan diperlukan suatu inovasi produk atau sebuah bahan ajar yang diharapkan dapat memberikan solusi dari masalah-masalah tersebut. Salah satunya adalah bahan ajar berupa modul pembelajaran yang dapat digunakan oleh siswa. Modul pembelajaran tersebut dapat dikembangkan berdasarkan kebutuhan, seperti pada masalah yang ditemukan oleh peneliti terkait dengan karakter kemandirian siswa serta penanaman nilai-nilai agama yang dirasa sangat perlu diberikan untuk siswa.

Penulis melakukan suatu penelitian terkait modul pembelajaran yang dapat mengembangkan karakter mandiri individu sekaligus menanamkan nilai-nilai Islam untuk mewujudkan individu yang memiliki akhlakul karimah. Tujuan dari penelitian ini 
Intan, Retno, M. Kholil. Pengaruh Modul Pembelajaran IPA... adalah untuk mengetahui pengaruh dari penggunaan modul pembelajaran IPA terintegrasi nilai agama dalam mengembangkan karakter mandiri siswa. Pembelajaran IPA dalam modul dikemas dengan menyajikan ayat-ayat Al-Quran terkait materi serta kisah Islami agar siswa tidak keliru dalam mempelajari teoti yang ada di alam semesta yang akan diperkuat dengan ilmu agama, maka dari itu modul pembelajaran ini dibuat dengan mengintegrasikan nilai agama.

\section{METODE}

Metode yang digunakan pada penelitian ini adalah kuasi eksperimen dengan desain penelitian pretest-posttest control group design yaitu menentukan kelas eksperimen dan kelas kontrol dengan cara membandingkan keadaan sebelum dan sesudah (before-after) menggunakan modul pembelajaran terintegrasi nilai agama. Dalam desain ini terdapat dua kelompok yang dipilih secara random kemudian diberi pretest untuk mengetahui keadaan awal adakah perbedaan antara kelompok eksperimen dan kelompok kontrol (Sugiyono, 2015: 112-113).

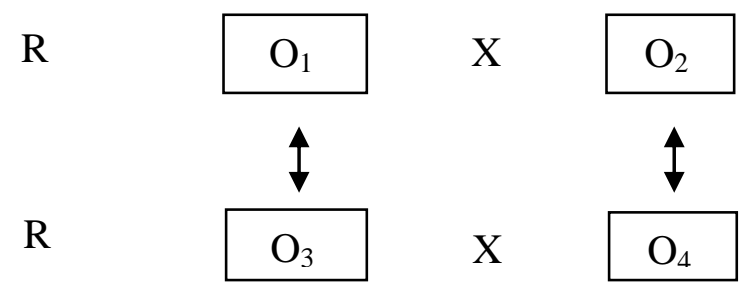

\section{Gambar 1. Desain eksperimen dengan kelompok kontrol.}

(Pretest-posttest control group desain)

Berdasarkan Gambar 1. dapat dijelaskan bahwa sebelum modul pembelajaran terintegrasi nilai agama dicobakan, maka dipilih terlebih dahulu kelas yang akan diajar menggunakan modul tersebut. Kelompok pertama yang akan diajar dengan menggunakan modul pembelajaran terintegrasi nilai agama disebut kelas eksperimen, sedangkan kelompok yang tidak menggunakan modul pembelajaran tersebut disebut kelas kontrol. Kedua kelompok tersebut selanjutnya diberikan pretest atau melalui pengamatan untuk mengetahui posisi awal (perkembangan karakter mandiri) pada dua kelompok tersebut. Jadi $\mathrm{O}_{1}$ adalah nilai awal kelas eksperimen, dan $\mathrm{O}_{3}$ adalah nilai awal kelas kontrol. Setelah itu, kelas eksperimen diberi treatment / perlakuan untuk diajar dengan menggunakan modul pembelajaran terintegrasi nilai agama, dan kelas kontrol 
Intan, Retno, M. Kholil. Pengaruh Modul Pembelajaran IPA... diajar tanpa menggunakan modul pembelajaran terintegrasi nilai agama. Dalam pengujian ini, $\mathrm{O}_{2}$ berarti hasil dari kelompok eksperimen setelah diajar dengan menggunakan modul pembelajaran terintegrasi nilai agama, dan $\mathrm{O}_{4}$ adalah hasil dari kelompok kontrol yang diajar tanpa menggunakan modul pembelajaran tersebut. Bila nilai $\mathrm{O} 2$ secara signifikan lebih tinggi dari O4, maka modul pembelajaran terintegrasi nilai agama terbukti berhasil untuk mengembangkan karakter mandiri siswa.

Tabel 1. Pembagian Kelas Eksperimen dan Kelas Kontrol

\begin{tabular}{|c|c|c|c|}
\hline Nama Sekolah & Jumlah Siswa & Kelas Eksperimen & Kelas Kontrol \\
\hline SDN Menteng & 62 & 29 & 33 \\
\hline SDN Semplak 2 & 70 & 35 & 35 \\
\hline Jumlah Total & $\mathbf{1 3 2}$ & $\mathbf{6 4}$ & $\mathbf{6 8}$ \\
\hline
\end{tabular}

Jumlah keseluruhan sampel pada penelitian ini sebanyak 132 siswa kelas 5 yang terdiri dari dua sekolah, yaitu SDN Menteng dan SDN Semplak 2 Kota Bogor tahun ajaran 2018/2019. Siswa kelas 5 SDN Menteng berjumlah 62 siswa yang terbagi menjadi dua kelas, yaitu kelas eksperimen sebanyak 29 siswa dan kelas kontrol sebanyak 33 siswa. Sementara itu siswa dari SDN Semplak 2 berjumlah 70 siswa yang juga terbagi menjadi dua kelas, yaitu kelas eksperimen sebanyak 35 siswa dan kelas kontrol sebanyak 35 siswa. Dari pembagian kelas tersebut, peneliti menggabungkan kelas eksperimen dan kontrol dari dua sekolah, sehingga jika digabungkan kelas eksperimen berjumlah 64 siswa yang diberikan perlakuan dengan menggunakan modul pembelajaran IPA terintegrasi nilai agama, sedangkan kelas kontrol berjumlah 68 siswa yang tidak diberikan perlakuan atau proses belajar masih konvensional menggunakan buku yang disediakan pemerintah.

Teknik pengumpulan pada penelitian ini yaitu dengan observasi yang bertujuan untuk mendapatkan data mengenai pengaruh modul pembelajaran IPA terintegrasi nilai agama terhadap karakter mandiri siswa. Dalam penelitian ini observasi yang dilakukan adalah pengamatan untuk mengamati kegiatan siswa dalam proses pembelajaran dengan menggunakan modul pembelajaran terintegrasi nilai agama untuk mengembangkan karakter mandiri siswa dan mengamati proses kegiatan belajar mengajar di kelas. 
Intan, Retno, M. Kholil. Pengaruh Modul Pembelajaran IPA...

Tabel 2. Karakter Mandiri yang Hendak Dicapai

\begin{tabular}{|c|c|}
\hline Karakter yang Dikembangkan & Indikator Pencapaian \\
\hline \multirow{13}{*}{ Mandiri } & 1. Berangkat ke sekolah sendiri \\
\hline & 2. Tidak bergantung pada teman \\
\hline & 3. Tidak bergantung pada guru \\
\hline & 4. Menyelesaikan masalahnya sendiri \\
\hline & $\begin{array}{l}\text { 5. Mengetahui dan melaksanakan ibadah tanpa harus } \\
\text { diinstruksikan oleh guru }\end{array}$ \\
\hline & 6. Mengerjakan tugas sendiri \\
\hline & 7. Berbagi tugas sesuai dengan perannya dalam kelompok \\
\hline & $\begin{array}{l}\text { 8. Melakukan kegiatan praktik sendiri melalui prosedur } \\
\text { yang telah disediakan guru }\end{array}$ \\
\hline & 9. Mengembangkan pengetahuannya sendiri \\
\hline & $\begin{array}{l}\text { 10. Menciptakan cara lain untuk menyelesaikan tugasnya } \\
\text { sendiri }\end{array}$ \\
\hline & 11. Membuang sampah pada tempatnya \\
\hline & 12. Menghemat penggunaan air \\
\hline & 13. Merawat tumbuhan yang ada di lingkungan sekolah \\
\hline
\end{tabular}

Teknik analisis data menggunakan software SPSS 20 for window. Data yang diperoleh akan diolah menggunakan uji Paired Samples T-Test untuk data yang dependent dan uji One Sample Test untuk data independent guna memperoleh hasil akhir berupa angka yang meunjukkan perubahan pada waktu belajar menggunakan modul dan belajar tidak menggunakan modul.

\section{HASIL}

Sebelum menganalisis data hasil observasi terlebih dahulu data tersebut dilakukan uji normalitas dan uji homogenitas untuk mengetahui data yang digunakan berdistribusi normal atau tidak dengan taraf $\alpha$ sebesar 0,05 . Untuk menguji normalitas dan homogenitas ini dibantu dengan aplikasi SPSS 20 for windows uji normalitas yang dilakukan dengan menggunakan rumus One Sampel Kolmogorov Smirnov.

Ho : sampel berdistribusi normal.

Ha : sampel tidak berdistribusi normal.

Pengambilan kesimpulan ini didasarkan kepada taraf signifikan yang diperoleh lebih besar dari 0,05, maka Ho diterima dan jika taraf signifikan lebih kecil dari 0,05, maka Ha diterima dan tolak Ho. Hasil uji normalitas ini diperoleh dari hasil kelas eksperimen dan kelas kontrol sebagai berikut : 
Intan, Retno, M. Kholil. Pengaruh Modul Pembelajaran IPA...

Tabel 3. Uji Normalitas

\begin{tabular}{|ll|r|}
\hline \multicolumn{2}{|c|}{ One-Sample Kolmogorov-Smirnov Test } \\
\hline $\mathrm{N}$ & $\begin{array}{c}\text { Unstandardize } \\
\text { d Residual }\end{array}$ \\
Normal Parameters ${ }^{\mathrm{a}, \mathrm{b}}$ & Mean & 128 \\
& Std. Deviation & 2.89098177 \\
& Absolute & .107 \\
Most Extreme Differences & Positive & .066 \\
& Negative & -.107 \\
Kolmogorov-Smirnov Z & & 1.210 \\
Asymp. Sig. (2-tailed) & & .107 \\
\hline
\end{tabular}

a. Test distribution is Normal.

b. Calculated from data.

Berdasarkan hasil pada Tabel 2. mengenai uji normalitas pada kelas eksperimen dan kelas kontrol maka diperoleh hasil sig (2-tailed) sebesar 0,107. Hasil ini menunjukan bahwa sig (2-tailed) lebih besar dari 0,05 maka Ho diterima dan tolak Ha. Dapat dikatakan bahwa data hasil tersebut berdistribusi normal.

\section{Tabel 4. Uji Homogenitas}

Test of Homogeneity of Variances

KarakterMandiri

\begin{tabular}{|c|c|c|c|}
\hline $\begin{array}{c}\text { Levene } \\
\text { Statistic }\end{array}$ & df1 & df2 & Sig. \\
\hline .298 & 1 & 126 & .586 \\
\hline
\end{tabular}

Berdasarkan hasil uji homogenitas pada Tabel 3. diperoleh hasil sig sebesar 0,586. Hal tersebut menunjukan bahwa sig lebih besar dari 0,05 dan dapat disimpulkan bahwa data tersebut bersifat homogen.

Setelah diketahui bahwa data berdistribusi normal dan bersifat homogen, selanjutnya dilakukanlah proses analisis data secara keseluruhan dengan mengolah hasil pretest dan posttest pada kelas eksperimen dan kelas kontrol dari dua sekolah sebagai berikut: 
Intan, Retno, M. Kholil. Pengaruh Modul Pembelajaran IPA...

Tabel 5. Paired Sample T-Test Karakter Mandiri Kelas Eksperimen

\begin{tabular}{|c|c|c|c|c|c|c|c|c|c|}
\hline & & \multicolumn{5}{|c|}{ Paired Differences } & \multirow[t]{3}{*}{$\bar{T}$} & \multirow[t]{3}{*}{ df } & \multirow{3}{*}{$\begin{array}{l}\text { Sig. (2- } \\
\text { tailed) }\end{array}$} \\
\hline & & \multirow[t]{2}{*}{ Mean } & \multirow[t]{2}{*}{$\begin{array}{c}\text { Std. } \\
\text { Deviation }\end{array}$} & \multirow[t]{2}{*}{$\begin{array}{l}\text { Std. Error } \\
\text { Mean }\end{array}$} & \multicolumn{2}{|c|}{$\begin{array}{l}95 \% \text { Confidence } \\
\text { Interval of the } \\
\text { Difference }\end{array}$} & & & \\
\hline & & & & & Lower & Upper & & & \\
\hline Pair 1 & $\begin{array}{c}\text { PretestAB } \\
- \\
\text { PostestAB }\end{array}$ & -6.92188 & 1.75757 & .21970 & -7.36090 & -6.48285 & -31.507 & 63 & .000 \\
\hline
\end{tabular}

Tabel 6. Paired Sample T-Test Karakter Mandiri Kelas Kontrol

\begin{tabular}{|c|c|c|c|c|c|c|c|c|}
\hline & \multicolumn{5}{|c|}{ Paired Differences } & \multirow[t]{3}{*}{$\mathbf{T}$} & \multirow[t]{3}{*}{ df } & \multirow{3}{*}{$\begin{array}{l}\text { Sig. (2- } \\
\text { tailed) }\end{array}$} \\
\hline & \multirow[t]{2}{*}{ Mean } & \multirow[t]{2}{*}{$\begin{array}{c}\text { Std. } \\
\text { Deviation }\end{array}$} & \multirow[t]{2}{*}{$\begin{array}{l}\text { Std. } \\
\text { Error } \\
\text { Mean }\end{array}$} & \multicolumn{2}{|c|}{$\begin{array}{c}95 \% \text { Confidence } \\
\text { Interval of the } \\
\text { Difference } \\
\end{array}$} & & & \\
\hline & & & & Lower & Upper & & & \\
\hline $\begin{array}{cc}\text { Pair } & \text { PretestAB - } \\
1 & \text { PostestAB }\end{array}$ & -3.30882 & 1.92592 & .23355 & -3.77500 & -2.84265 & -14.167 & 67 & .000 \\
\hline
\end{tabular}

Hasil data pada Tabel 5. dan Tabel 6. mengenai perhitungan paired sampel t-test pada kelas eksperimen dan kelas kontrol terlihat perbedaan rata-rata antara pretest dan posttest pada kelas eksperimen sebesar -6.92188 sedangkan pada kelas kontrol diperoleh perbedaan rata-rata sebesar -3.30882. Tanda minus (-) berarti hasil posttest lebih besar dari pada hasil pretest. Hasil perbedaan rata-rata kedua kelas tersebut menunjukan perbedaan sebelum dan sesudah. Penilaian secara keseluruhan tersebut pun mengalami peningkatan, namun peningkatan yang lebih besar berada pada kelas eksperimen. Artinya ada pengaruh dari penggunaan modul pembelajaran IPA terintegrasi nilai-nilai agama yang dibuktikan dengan perbedaan rata-rata pada kelas eksperimen dan kelas kontrol sebesar 3.61306. 
Intan, Retno, M. Kholil. Pengaruh Modul Pembelajaran IPA...

Hasil perhitungan nilai " $t$ ” pada kelas eksperimen sebesar 31.507 dengan p-value 0,000 sig (2-tailed). Sedangkan pada kelas kontrol nilai “t” sebesar 14.167 dengan pvalue 0,000 sig (2-tailed). Hal ini berarti Ho ditolak dan Ha diterima. Maka dapat disimpulkan secara statistika adanya perbedaan yang signifikan antara hasil rata-rata pretest dan posttest. Secara statistika perbedaan terbesar terjadi pada kelas eksperimen yang diberikan perlakuan dengan menggunakan modul pembelajaran IPA terintegrasi nilai agama.

Berdasarkan hasil pretest dan posttest pada perhitungan paired sampel t-test mengenai nilai kelas eksperimen dan kelas kontrol. Maka dapat dilakukan analisis dengan menggunakan independent sampel t-test untuk mengetahui hasil perhitungan posttest pada kelas kontrol dan kelas eksperimen, berikut hasil data independent sampel t-test :

\section{Tabel 7. Independent Sampel T-Test Karakter Mandiri Kelas Eksperimen dan Kelas Kontrol}

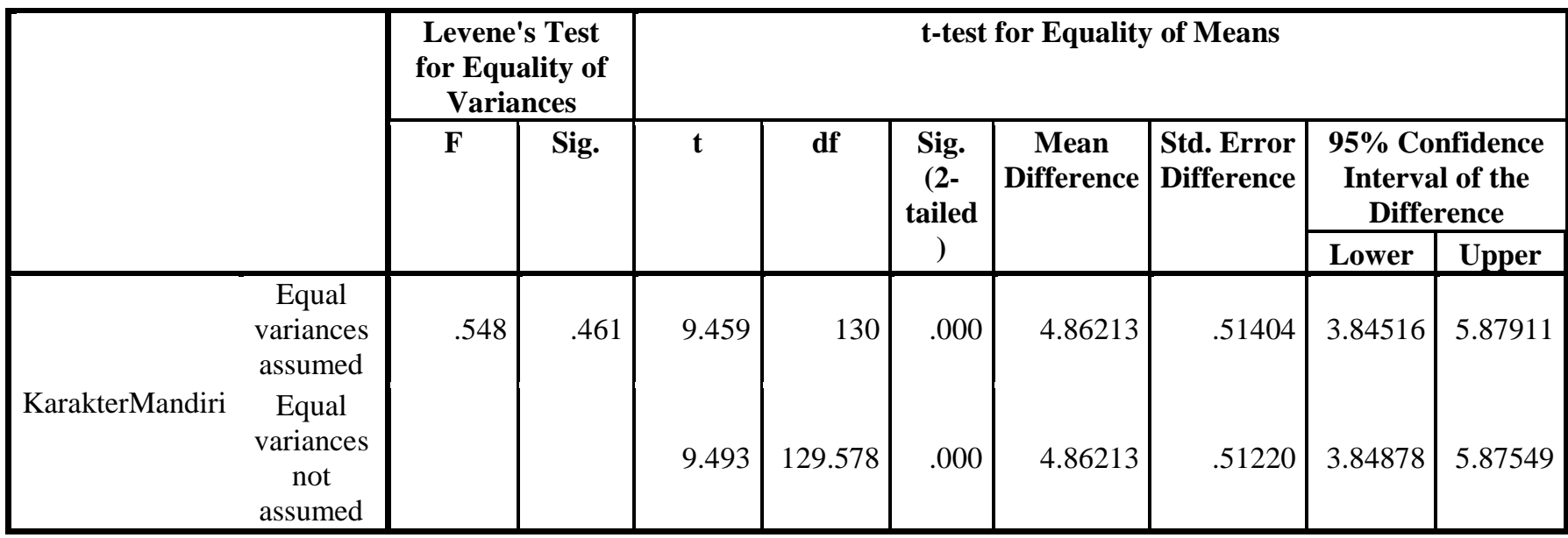

Hasil perhitungan pada Tabel 5. pada data independent sampel t-test diperoleh perbedaan rata-rata kelas eksperimen dan kelas kontrol secara keseluruhan sebesar 4.86213. Hasil tersebut diperoleh dari responden kelas eksperimen dan kelas kontrol, dengan p-value sig (2-tailed) sebesar 0,000. Maka Ha diterima dan terdapat perbedaan yang signifikan antara posttest kelas eksperimen dan hasil posttest kelas kontrol yang berarti bahwa terdapat peningkatan karakter mandiri pada siswa. Hasil yang diperoleh pada Tabel 3. mengenai paired sampel t-test kelas eksperimen terdapat peningkatan karakter mandiri yang signifikan dengan p-value sig (2-tailed) 0,000. Hal tersebut 
Intan, Retno, M. Kholil. Pengaruh Modul Pembelajaran IPA... menunjukan bahwa penggunaan modul pembelajaran IPA terintegrasi nilai-nilai agama berpengaruh dalam mengembangkan karakter mandiri siswa.

\section{PEMBAHASAN}

Modul pembelajaran IPA terintegrasi nilai-nilai agama sesuai dengan konsep Islamisasi sains yaitu dengan menggabungkan pengetahuan umum dengan nilai-nilai Islam. Penyampaian materi yang diiringi dengan penyampaian dalil dalam Al-Quran akan sangat membantu siswa dalam memahami materi pembelajaran. Dari konsep penjelasan tersebut peneliti dapat mengembangkan sebuah modul pembelajaran yang mengintegrasikan antara nilai-nilai agama dengan salah satu ilmu umum yaitu Ilmu Pengetahuan Alam (IPA), sebab kebenaran sesungguhnya hanya terdapat pada AlQur'an sehingga sangat penting mengintegrasikan nilai-nilai agama ke dalam ilmu pengetahuan umum lainnya. Menurut Mukaromah (2018: 198) walaupun sains modern telah banyak memberikan manfaat dan kemajuan dalam berbagai bidang bagi manusia, namun hal tersebut juga tidak terlepas dari dampak negatifnya, yaitu jauhnya nilai-nilai agama dalam kehidupan manusia. Modul pembelajaran IPA yang diintegrasikan dengan nilai-nilai agama ini memiliki tujuan agar siswa tidak hanya memiliki pengetahuan dari teori-teori ilmiah saja akan tetapi untuk menanamkan keyakinan pada siswa bahwa ilmu pengetahuan alam sangat berkitan dengan nilai-nilai agama serta dapat membentuk karakter siswa.

Berdasarkan hasil pemaparan mengenai pengaruh dari modul pembelajaran IPA terintegrasi nilai agama terhadap karakter mandiri siswa menunjukkan bahwa adanya peningkatan hasil rata-rata setelah menggunakan modul pembelajaran IPA terintegrasi nilai agama. Pada Tabel 5. yaitu tabel mengenai hasil perbedaan rata-rata nilai pretest dan posttest pada kelas eksperimen sebesar 6.92188, sedangkan pada kelas kontrol diperoleh perbedaan rata-rata sebesar 3.30882. Artinya ada pengaruh dari penggunaan modul pembelajaran IPA terintegrasi nilai-nilai agama yang dibuktikan dengan perbedaan rata-rata pada kelas eksperimen dan kelas kontrol sebesar 3.61306. Sejalan dengan apa yang dijelaskan oleh Rahayu, Pratikto, dan Rahayu (2016: 226) bahwa konsep modul kontekstual bermuatan karakter yaitu untuk menambah semangat belajar siswa yang dilengkapi dengan contoh-contoh yang terjadi langsung dalam dunia nyata serta lingkungan sekitar siswa agar siswa cepat memahami materi serta adanya 
Intan, Retno, M. Kholil. Pengaruh Modul Pembelajaran IPA...

tambahan tugas dan refleksi diri dalam modul agar siswa dapat mempelajari sekaligus menerapkan karakter secara sistematis dan berkesinambungan. Selain itu, menurut Octaviani (2017: 94) kegiatan pembelajaran akan bermakna jika peserta didik memperoleh pengalaman langsung dan terlatih untuk dapat menemukan sendiri berbagai pengalaman yang dipelajarinya, kemudian menghubungkannya dengan konsep lain yang telah dipahaminya.

Hal tersebut menunjukkan bahwa modul pembelajaran memberikan pengaruh serta manfaat untuk siswa hal ini sesuai dengan pernyataan Basri (2015 : 145-147) bahwa, "manfaat modul pembelajaran bagi siswa diantaranya adalah memiliki kesempatan untuk menguji kemampuan diri sendiri dengan mengerjakan latihan yang disajikan dalam modul, mengembangkan kemampuan peserta didik untuk berinteraksi langsung dengan lingkungan dan sumber belajar lainnya". Hal ini juga sesuai dengan penelitian yang dilakukan oleh N. Izzati, N. Hindarto, dan S. D. Pamelasari (2013: 187) peningkatan karakter mandiri terjadi karena responden sudah mampu melakukan kegiatan pembelajaran dengan mandiri sesuai dengan fungsi modul sebagai sarana untuk membelajarkan siswa secara mandiri. Berdasarkan hasil penelitian yang dilakukan oleh Trimantoto (2016: 222) pembelajaran dengan menggunakan modul juga mendapatkan respon yang baik dari siswa sehingga hasil belajar siswa dapat meningkat dikarenakan dalam modul siswa diajak untuk dapat belajar mandiri maupun kelompok dan dapat mengukur kemampuan belajarnya sendiri melalui soal-soal yang terdapat pada modul, serta materi yang ada pada modul dikemas dengan menarik dan memperhatikan karakteristik siswa.

\section{SIMPULAN}

Modul pembelajaran IPA terintegrasi nilai agama berpengaruh dalam meningkatkan karakter mandiri siswa. Peneliti membuktikan hal tersebut melalui perolehan data hasil observasi nilai posttest karakter mandiri siswa kelas eksperimen dan kelas kontrol yang diuji menggunakan One Sample T-Test menunjukkan angka t hitung antara kelas kontrol dan kelas eksperimen yaitu 31.507 kelas eksperimen dan 14.167 kelas kontrol. Dengan demikian terjadi perbedaan hasil sebesar 17,34 yang berarti terdapat pengaruh yang signifikan dari modul pembelajaran IPA terintegrasi nilai agama terhadap karakter mandiri yang nyata pada siswa kelas eksperimen yaitu kelas 
Intan, Retno, M. Kholil. Pengaruh Modul Pembelajaran IPA... yang diberikan perlakuan dengan belajar menggunakan modul sehingga $\mathrm{Ha}$ dapat diterima.

\section{UCAPAN TERIMAKASIH}

Ucapan terima kasih penulis sampaikan kepada Kepala SDN Semplak 2 Kota Bogor dan Kepala SDN Menteng Kota Bogor yang telah bersedia membantu menyediakan tempat penelitian serta kepada beberapa pihak yang telah terlibat serta berkontribusi secara langsung dalam proses penelitian ini.

\section{DAFTAR RUJUKAN}

Basri, Hasan. 2015. Paradigma Baru Sistem Pembelajaran. Bandung: Pustaka Setia.

Ditasari, Peniati, dan Kasmui. 2013. Pengembangan Modul Pembelajaran IPA Terpadu Berpendekatan Keterampilan Proses pada Tema Dampak Limbah Rumah Tangga Terhadap Lingkungan untuk SMP Kelas VIII. Unnes Sciences Education Journal, 2: 331.

Faizah, Silvia Nur. 2017. Pengembangan Modul IPA Berbasis Integrasi Islam dan Sains dengan Pendekatan Inkuiri di MI Salafiyah Kutukan Blora. AT-THULAB, 1: 103.

Gunawan, Suyitno, dan Supriyadi. 2018. Nilai Pendidikan Karakter Religius dan Cinta Tanah Air Novel Rantu 1 Muara Karya Ahmad Fuadi. Jurnal AKADEMIKA, 23: 341.

Huda, Miftahul. 2014. Model-Model Pengajaran dan Pembelajaran. Yogyakarta: Pustaka Pelajar.

Istanti, Vanti. 2015. Pengembangan Modul Ilmu Pengetahuan Alam Bagi Siswa Kelas IV Sekolah Dasar. Artikel Teknologi Pendidikan.

Izzati, Hindarto, dan Pamelasari. 2013. Pengembangan Modul Tematik dan Inovatif Berkarakter pada Tema Pencemaran Lingkungan untuk Siswa Kelas VII SMP. Jurnal Pendidikan IPA Indonesia, 2: 187.

Maman. 2012. Pola Berpikir Sains: Membangkitkan Kembali Tradisi Keilmuan Islam. Bogor: QMM Publishing.

Mukaromah, Siti Maulidatul. 2018. Pengembangan Modul IPA Braille Berbasis Integrasi Islam dan Sains. INKLUSI: Journal of Disability Studies, 5: 198. 
Intan, Retno, M. Kholil. Pengaruh Modul Pembelajaran IPA...

Nurjanah, Fenti. 2018. Pengembangan Bahan Ajara Tematik Terintegrasi Nilai-Nilai Islam dan Sains untuk Meningkatkan Karakter Religius Siswa. Jurnal Ilmiah Pendidikan Dasar, 3: 185.

Octaviani, Srikandi. 2017. Pengembangan Bahan Ajar Tematik dalam Implementasi Kurikulum 2013 Kelas 1 Sekolah Dasar. Jurnal Pendidikan Dasar: EduHumaniora, 9: 94.

Prastowo, Andi. 2014. Panduan Kreatif Membuat Bahan Ajar Inovatif. Jogjakarta: DIVA Press.

Rahayu, Pratikto, dan Rahayu. 2016. Pengembangan Modul Pembelajaran Kontekstual Bermuatan Karakter pada Mata Pelajaran Kewirausahaan di SMK Cendika Bangsa Kepajen. Jurnal Pendidikan Bisnis dan Manajemen, 2: 226.

Sugiyono. 2015. Metode Penelitian Pendidikan: Pendekatan Kuantitatif, Kualitatif, dan $R \& D$. Bandung: Alfabeta.

Trimantoto, Achmad Subekti. 2016. Pengembangan Modul Pembelajaran Tematik "Merawat Hewan dan Tumbuhan" Tema 7 untuk Siswa Kelas 2 SD. E-Jurnal Prodi Teknologi Pendidikan, 5: 222. 